\title{
THE IMPACT OF SimUlation ON TEACHING EFFECTIVENESS AND STUDENT LEARNING PERFORMANCE
}

\author{
Abdullah Alenezi \\ Northern Borders University,Arar,Saudi Arabia
}

\begin{abstract}
Simulation Strategy Is Increasingly Becoming A Popular Educational Tool In The Production Of Highly Qualified Professionals In The Field Of Education, Health, And Applied Sciences. Particularly, The Strategy Helps Improve Teaching Practice Effectiveness And Student Learning Performance. This Research Paper Aimed At Investigating The Effectiveness Of Simulation In Teaching And Student Learning Performance In The University Context. The Study Was Important Since It Highlighted How Different Kinds Of Simulation Improve Teaching Practice Effectiveness And Student Learning Performance. The Explanatory Research Design Was Used In This Research Where Data Was Collected Using Close-Ended Questionnaires Designed To Utilize Likert Scale Described In The Methodology Section. The Study Targeted 150 Student Participants. However, Only 134 Students Filled And Returned Their Questionnaires. Both Descriptive And Statistical Analysis Techniques Were Applied In This Research. Descriptive Statistics, Particularly Percentages Were Used In Describing Participant Information. Also, Statistical Analysis Was Used In Determining Reliability Of The Questionnaire As Well As For Hypothesis Testing. The Study Indicated That Social Process Simulation, Diagnostic Simulation, And Data Management Simulation Have A Statistically Significant Positive Relationship With Teaching Practice Effectiveness And Student Learning Performance. Based On The Findings, It Was Concluded And Recommended That Teachers And Students Should Accept The Use Of Simulation In Their Classroom To Enhance Their Classroom Outcomes.
\end{abstract}

\section{KEYWORDS}

Simulation, educational tool, teaching effectiveness, learning performance, variables, university context

\section{INTRODUCTION}

The concern for teaching that has been on the limelight for many years is to reduce the number of students dropping out of a given course as a result of improved learning outcomes. López-Pérez et al. (2011) argued that achieving such an aim needed a change in the way teacher offer instructions. Traditionally, lectures and teachers in higher learning institutions used face-to-face instructional methods. As technology including internet and educational tools has advanced, virtual learning has become more popular. Compared to face-to-face instruction, virtual instruction can significantly increase cognitive-emotional engagement of the learners (PytlikZillig et al., 2011), gives learners more time to learn, offer opportunities to interact with other learners and fosters an environment that promotes better attitudes and achievement (Yamat, 2013). With face to face teaching, educators have an opportunity to offer prompt feedback to students, increasing interactivity in the classroom and enhance decision making in the discussions (Yamat, 2013). In this regard, higher learning institutions have blended both face-to-face teachings as well as virtual teaching to enhance student education. López-Pérez et al. (2011) view blended learning as the integration of virtual activities to tradition instructional activities. The blended classroom is advantageous since it has both the benefits of traditional and virtual learning activities. This 
International Journal on Integrating Technology in Education (IJITE) Vol.8, No.3, September 2019 implies that blended classrooms are more likely to affect the learning performance of students. Blended learning in higher learning institutions involves the use of strategies such as video communication, face-to-face lecture and simulation among others (Hopwood, Rooney, Boud, \& Kelly, 2016).

This research paper's main focus is directed towards the effectiveness of simulation in teaching and learning in higher learning settings. Simulation is regarded as an educational approach for learning as well as teaching applicable to different disciplines (Hopwood, Boud, \& Kelly, 2015). Moreover, learning that is based on simulation promotes the development of knowledge, attitudes, and skills of professionals whilst protecting unnecessary risks among consumers (Hopwood et al., 2015). Since simulation is essential in training and education, the focus of the paper is students' learning behavior. Performance of teachers and students is improved when using the simulation strategy. Also, students have an opportunity to apply knowledge into practice in a virtual environment to facilitate the acquisition of new skills in an efficient manner guided by the educators (Rooney et al., 2015). Different students from different majors have varying reactions associated with simulation application as a learning tool. This is because educators use different kinds of instructional content on their students making reactions regarding simulation to be different (O'Connor, Mortimer, \& Bond, 2011). Students taking business as a major prefer instruction using videos, charts, slides, and shows. Similarly, they prefer instruction modes supporting relationship building with educators and peers for teamwork in accomplishing assignments (Miller, 2016; Vos, 2015; Xu \& Yang, 2010). On the other hand, students taking engineering, nursing, and computer science as their major prefer application of new technologies that are not provided in tradition teaching methods, such as blended learning classes as well as collaborative classes (Liou, Yu, Tsai, \& Cheng, 2015; Clark, Kaw, \& Besterfield-Sacre, 2016; Grover, Pea, \& Cooper, 2015; Dang, Zhang, Ravindran, \& Osmonbekov, 2016).

In such disciplines, the effectiveness of simulation has been found to yield mixed results. For instance, some of the studies have revealed that simulation has positive impacts on the mastery of content (Franklin \& Lee 2014; McCoy, 2017). In the social science discipline related courses, class simulations have been found to improve the academic performance of students and teacher outcomes compared to the traditional lecture method. Auman (2011) revealed that compared to the traditional lecture classroom, classes adopting simulation increased levels of classroom engagement for teachers and students. However, Raymond (2010) found traditional-based and simulation-based pedagogy to promote equal performance classroom outcomes. Simulation has also been found to improve academic performance of the students in comparison to the lecturebased method (Dolvin \& Pyles, 2018; Hwang \& Hahn, 2017). Finally, simulation-based pedagogy as noted by Guy and Lownes-Jackson (2015) improve student performance changing their behaviors, enhancing knowledge and providing best experiences.

Significant previous research studies focus more on simulation effectiveness on the learning achievement, but little research has explored factors in the simulation strategy that are associated with student or teacher performance as well as the kind of performance that can be impacted. This topic is fundamental in deciding the type of simulation which fits a given group of individuals and chances that can be made to the existing simulation strategies to make it more effective in teaching and learning. Types of simulation include experimental (social simulation, diagnostic simulation, data management simulations) and symbolic/computer-based simulation (Auman, 2011; Miller, A. (2016; Xu \& Yang, 2010). Moreover, in the education sector, occasionally educators have integrated simulation as an educational tool to offer effective instruction improving learning (Taher \& Khan, 2015). This is because they may not have an idea of how simulation affects student learning as well as teaching outcomes. Based on this research, the interests in the simulation strategy will be invoked by demonstrating that this method of instruction has a positive association with teaching and learning performance outcomes. 
International Journal on Integrating Technology in Education (IJITE) Vol.8, No.3, September 2019 Therefore, this research was aimed at investigating the impact of simulation in student learning performance as well as teaching effectiveness in the university context. This is to highlight the association between kinds of simulation and teaching as well as learning performance of students.

\section{RESEARCH QUESTIONS}

The overall research question stated: What is the impact of using different kinds of simulation on teaching as well as student learning performance? Other research questions included:

- How does social process simulation impact teaching practice effectiveness?

- How does diagnostic simulation impact teaching practice effectiveness?

- How does data management simulation impact teaching practice effectiveness

- How does social process simulation impact on student learning performance?

- How does diagnostic simulation impact student learning performance?

- How does data management simulation impact student learning performance?

\section{HYPOTHESES}

H1: The use of social process simulation has a statistically significant positive impact on teaching practice effectiveness.

$\mathrm{H} 2$ : The use of diagnostic simulation has a statistically significant positive impact on teaching practice effectiveness.

H3: The use of data management simulation has a statistically significant positive impact on teaching practice effectiveness.

H4: The use of social process simulation has a statistically significant positive impact on student learning performance.

H5: The use of social process simulation has a statistically significant positive impact on student learning performance.

H6: The use of social process simulation has a statistically significant positive impact on student learning performance.

\section{Methodology}

The study falls within the paradigm of the explanatory research approach. The design was used in this research paper because it could offer the researcher an opportunity to study variables to determine causal-effective associations between those variables (Rahi, 2017). In this regard, the aim of the study was achieved by examining independent variables associated with experimental simulations as well as symbolic simulations as well as dependent variables associated with student learning performance and effective teaching practice. The study population was selected from University students currently enrolled in the academic program in different Saudi Universities. The sample for this research paper consisted of 150 student participants that were selected using the snowballing sampling technique from 15 universities. Snowballing technique is for selecting individuals to recruit study participants (McGarry, Green, \& Fowler, 2018). With snowballing sampling technique, the researcher selected 10 participants who were for purposes of recruiting friends they know are currently enrolled in the university program in Saudi Arabia. From each university 10 students were selected to give their views on the impact of simulation on teaching practice effectiveness and their learning performance. However, only 134 students filled and returned their questionnaires. 
International Journal on Integrating Technology in Education (IJITE) Vol.8, No.3, September 2019

\section{Data Collection InStrument}

The instrument for this research entailed closed-ended questionnaire designed to use Likert scale (1=strongly disagree, 2=disagree, $3=$ neutral, 4=agree, and 5=strongly agree) (Joshi, Kale, Chandel, \& Pal, 2015). The questionnaire comprised of two parts. The first one was for collecting demographic information of the participants while the second one was for collecting information associated with the effectiveness of simulation on teaching and learning. The procedure for data collection included identifying the 150 student participants and seeking their consent to take part in this research.

\section{Data collection procedure}

Ethical approval was sought from (include university name)'s Institutional Research Board (IRB). This research was free of risks associated with social, physical, psychological and economic harm because a non-invasive questionnaire was used. After agreeing to participate, the questionnaires were administered to them via their emails after consenting and were given one and a half weeks to return filled questionnaires. The expected response rate was at least $50 \%$. The completed questionnaires were downloaded and imported into SPSS software for the statistical and descriptive analysis described below.

\section{Data analysis}

Since quantitative data was collected for this research and was aimed at examining the causaleffective associations between the dependent and independent variables, statistical methods were used in the analysis of data. Also, descriptive statistics were used in examining the demographics of the student participants. Statistical methods are models or techniques for statistical analysis of raw data (Albers, 2017). Using this method, the reliability of the findings was evaluated. Reliability, defined as the internal consistency of the questionnaire items, was evaluated using the Cronbach's Alpha coefficient. With a value more than .70, the internal consistency is satisfactory (Heale \& Twycross, 2015; Martini et al., 2015)implying that the questionnaire instrument was fit for collecting data to understand the impact of simulation in teaching practice effectiveness and student learning performance outcomes. After analyzing reliability, hypotheses were tested using multiple linear regression model. Using the model, two features were used in examining the data, these include R-square and R-value column value. $\mathrm{R}$-value is used in determining whether the model was fit for the collected data and R-square is determining whether the variation in the dependent variable can be explained based on the variations in the independent variables. A model is acceptable to be fit for the collected data if the R-value is more than .70 (Cohen, West, \& Aiken, 2014). Additionally, the model coefficients, B and p-values were used. The B-value was for assessing whether there is an association between dependent and independent variables and if the association is positive or negative/inverse. Finally, the p-value was for testing the statistical significance of the associations establishing to confirm or reject the hypotheses. If it is less than .05 , the given hypothesis is confirmed and if it is more than .05 , the hypothesis is rejected (Cohen et al., 2014).

\section{Compliance with Ethical Standards}

The author declare that there is no conflict of interest regarding the publication of this paper. The research received no funding from any institution or individual .Since the study involved human participants, as recommended by the IRB, two considerations were made to ensure research ethics associated with anonymity and confidentiality was guaranteed. For anonymity, the researcher ensured there was no sensitive information from the participant was revealed to the public. Also, the real names of participants were not used in data collection or during the compilation of this 
International Journal on Integrating Technology in Education (IJITE) Vol.8, No.3, September 2019 journal (Colnerud, 2013). For confidentiality, the researcher ensured all data associated with the participants was stored safely in password-protected computers accessed by the research only. Similarly, participants were assured of data destruction after the publication of the journal (Colnerud, 2013).

\section{RESULTS AND DISCUSSION}

The section presents findings after quantitative data analysis. Moreover, it begins with the descriptive statistics of the demographic information of participants and then followed by the inferential statistics. Finally, a discussion of the findings is presented.

\section{Demographic information of the participants}

Table 1.Gender distribution of participants

\begin{tabular}{|ll|l|l|l|l|}
\hline Gender & & Frequency & Percent & $\begin{array}{l}\text { Valid } \\
\text { Percent }\end{array}$ & $\begin{array}{l}\text { Cumulative } \\
\text { Percent }\end{array}$ \\
\hline \multirow{2}{*}{ Valid } & 1 & 101 & 39.9 & 75.4 & 75.4 \\
& Total & 33 & 13.0 & 24.6 & 100.0 \\
Missing & System & 119 & 53.0 & 100.0 & \\
Total & & 253 & 47.0 & & \\
\hline
\end{tabular}

The number of participants who were female was more compared to the ones who were males as indicated in table 1 (female-75.4\% and male-24.6\%). However, the data indicated that both male and female students participated in the study to highlight the impact of simulation on teaching and learning.

Table 2. Participant distribution based on year of study

\begin{tabular}{|ll|l|l|l|l|}
\hline Year of study & Frequency & Percent & $\begin{array}{l}\text { Valid } \\
\text { Percent }\end{array}$ & Cumulative Percent \\
\hline \multirow{4}{*}{ Valid } & 1 & 17 & 6.7 & 12.7 & 12.7 \\
& 2 & 26 & 10.3 & 19.4 & 32.1 \\
& 4 & 8 & 3.2 & 6.0 & 38.1 \\
& 5 & 24 & 9.5 & 17.9 & 56.0 \\
& Total & 59 & 23.3 & 44.0 & 100.0 \\
Missing & System & 134 & 53.0 & 100.0 & \\
Total & & 253 & 47.0 & & \\
\hline
\end{tabular}

The distribution of participants as indicated in table 2 based on their year of study is as follows. First, $12.7 \%$ of the participants were first-year students while $19.4 \%$ of the participants were second-year students. Additionally, 6.0\% of the students were third Year University students as $17.9 \%$ of them were fourth-year students. Finally, $44 \%$ of the participants were fifth-year students. This distribution shows that all categories of students enrolled in universities in Saudi Arabia were included in this study to give individual views based on their experiences. 
International Journal on Integrating Technology in Education (IJITE) Vol.8, No.3, September 2019

Table 3.Participant distribution based on their university department

\begin{tabular}{|ll|l|l|l|l|}
\hline Department & Frequency & Percent & $\begin{array}{l}\text { Valid } \\
\text { Percent }\end{array}$ & Cumulative Percent \\
\hline & 1 & 30 & 11.9 & 22.4 & 22.4 \\
& 3 & 18 & 7.1 & 13.4 & 35.8 \\
Valid & 4 & 29 & 11.5 & 21.6 & 57.5 \\
& 5 & 29 & 6.3 & 11.9 & 69.4 \\
& 6 & 12 & 11.5 & 21.6 & 91.0 \\
& Total & 134 & 4.7 & 9.0 & 100.0 \\
Missing & System & 119 & 53.0 & 100.0 & \\
Total & & 253 & 100.0 & & \\
\hline
\end{tabular}

Based on the department the students were enrolled, $22.4 \%$ of the student participants were from the engineering and technology department while $13.4 \%$ of them were from the department of business. Additionally, $21.6 \%$ of the students were from the school or department of medicine as $11.9 \%$ were from the nursing department. Lastly, $21.6 \%$ and $9 \%$ of the students who participated in this study were from the departments of education and applied science respectively (see table 3 ). This indicates that almost all major departments of the university were represented in this study.

Table 4. Age distribution of participants

\begin{tabular}{|c|c|c|c|c|c|}
\hline \multicolumn{2}{|l|}{ Age } & Frequency & Percent & $\begin{array}{l}\text { Valid } \\
\text { Percent }\end{array}$ & $\begin{array}{l}\text { Cumulative } \\
\text { Percent }\end{array}$ \\
\hline \multirow{6}{*}{ Valid } & 1 & 17 & 6.7 & 12.7 & 12.7 \\
\hline & 2 & 84 & 33.2 & 62.7 & 75.4 \\
\hline & 3 & 25 & 9.9 & 18.7 & 94.0 \\
\hline & 4 & 5 & 2.0 & 3.7 & 97.8 \\
\hline & 5 & 3 & 1.2 & 2.2 & 100.0 \\
\hline & Total & 134 & 53.0 & 100.0 & \\
\hline Missing & System & 119 & 47.0 & & \\
\hline Total & & 253 & 100.0 & & \\
\hline
\end{tabular}

As shown in table $4,12.7 \%$ of the participants were aged between 17-19 years while many of them $(62.7 \%)$ were aged between $20-22$ years. Among the participants, $18.7 \%$ were aged between 23-25 years. Moreover, 3.7\% of the participants were aged between 26 and 28 years. Participants who were more than 28 years were $2.2 \%$. Similarly, these results indicated that student categories based on their age were represented in this research.

\section{Reliability of the instrument}

This section examines whether the questionnaire instrument for collecting data was reliable in exploring the impact of simulation on teaching and learning in universities. 
International Journal on Integrating Technology in Education (IJITE) Vol.8, No.3, September 2019

Table 5. Reliability of the questionnaire Reliability Statistics

\begin{tabular}{|l|l|}
\hline Cronbach's Alpha & $\mathrm{N}$ of Items \\
\hline .739 & 6 \\
\hline
\end{tabular}

As shown in table 5 the value for Cronbach's Alpha is .739 , which is more than the acceptable value of .70. This implies that the questionnaire developed was reliable in examining the impact of simulation on teaching practice effectiveness and student learning performance.

\section{Multiple Linear Regression Analysis}

\section{Impact of simulation on teaching practice effectiveness}

Table 6. Multiple linear regression model summary Model Summary

\begin{tabular}{|l|l|l|l|l|}
\hline Model & $\mathrm{R}$ & $\mathrm{R}$ Square & $\begin{array}{l}\text { Adjusted } \\
\text { Square }\end{array}$ & $\begin{array}{l}\mathrm{R} \\
\text { Std. Error of the } \\
\text { Estimate }\end{array}$ \\
\hline 1 & $.879^{\mathrm{a}}$ & .772 & .767 & .403 \\
\hline
\end{tabular}

a. Predictors: (Constant), DMS, DS, SPS

The R-value is .879 (87.9\%) indicating that the model is $87.9 \%$ fit for the collected data. also, the value for R-square is $.772(77.2 \%)$ showing that $77.2 \%$ of the variations in the dependent variable can be explained based on the variations in the independent variables (see table 6).

Table 7. Multiple model coefficients Coefficients

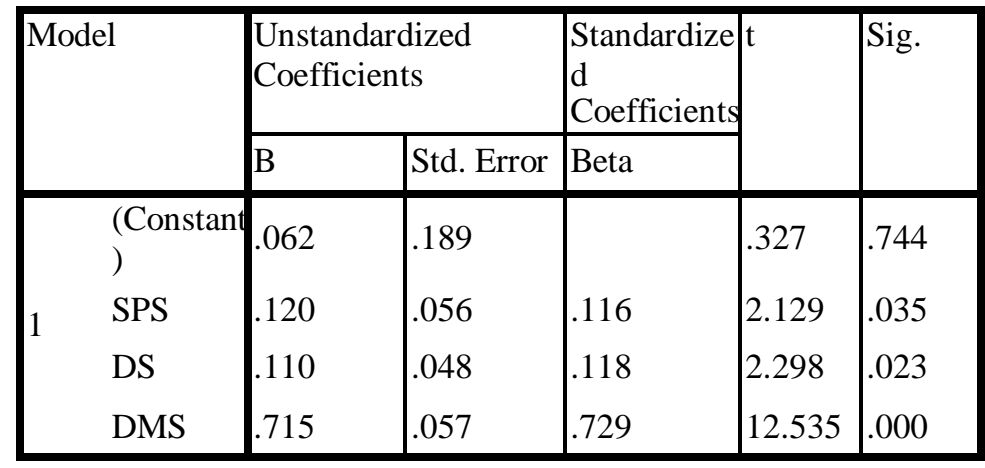

a. Dependent Variable: ITP

As shown in table 7, for SPS, $t=2.129, \mathrm{~B} .120$ and $\mathrm{p}=.035$. These results indicate that the associations between different social process simulation (SPS) and teaching practice effectiveness are positive. With an increase in SPS by one unit, it means that teaching practice effectiveness will increase by $12.0 \%$. Since $p<.05$, the association is statistically significant. As such, hypothesis 1 , the use of social process simulation has a positive and statistically significant impact on teaching practice effectiveness, is confirmed. For diagnostic simulation, $\mathrm{t}=2.298, \mathrm{~B}$, .110 and $\mathrm{P}=.023$. This indicates a positive relationship between diagnostic simulation and teaching practice effectiveness. As diagnostic simulation utilization is increased by one unit, teaching practice effectiveness is enhanced by $11.0 \%$. $\mathrm{P}<.05$ showing that the relationship is statistically significant. Therefore, hypothesis two, the use of diagnostic simulation has a positive and statistically significant impact on teaching practice effectiveness, is confirmed. Lastly, for data management simulation (DMS) the B-value is .715 indicating that an increase in DMS by 
International Journal on Integrating Technology in Education (IJITE) Vol.8, No.3, September 2019 one unit increases teaching practice effectiveness by $71.5 \%$. In this regard, hypothesis three, the use of data management simulation has a positive and statistically significant impact on teaching practice effectiveness, is confirmed.

Impact of simulation on student learning performance

Table 8. Multiple linear regression model summary Model Summary

\begin{tabular}{|l|l|l|l|l|}
\hline Model & $\mathrm{R}$ & $\mathrm{R}$ Square & $\begin{array}{l}\text { Adjusted } \\
\text { Square }\end{array}$ & $\begin{array}{l}\mathrm{R} \\
\text { Std. Error of the } \\
\text { Estimate }\end{array}$ \\
\hline 1 & $.749^{\mathrm{a}}$ & .561 & .551 & .566 \\
\hline
\end{tabular}

a. Predictors: (Constant), DMS, DS, SPS

As indicated in table 8, the R-value for the model is .749 (74.9\%). This shows that the model was fit for the collected data since it is more than $.70(70 \%)$ that is the acceptable value as indicated earlier. With the R-square value of .561 (56.1\%), the results indicated that the multiple linear regression model can explain $56.1 \%$ of the variations in the dependent variable (improved student learning performance) based on the variations in the independent variables (social process simulation, diagnostic simulation, and data management simulation).

Table 9. Multiple model coefficients Coefficients

\begin{tabular}{|c|c|c|c|c|c|c|}
\hline & \multirow[t]{2}{*}{ Model } & \multicolumn{2}{|c|}{ Unstandardized Coefficients } & \multirow{2}{*}{$\begin{array}{r}\begin{array}{r}\text { Standardized } \\
\text { Coefficients }\end{array} \\
\text { Beta } \\
\end{array}$} & \multirow[t]{2}{*}{$\mathrm{t}$} & \multirow[t]{2}{*}{ Sig. } \\
\hline & & B & Std. Error & & & \\
\hline \multirow{4}{*}{1} & (Constant) & .366 & .266 & & 1.378 & .170 \\
\hline & SPS & .443 & .079 & .424 & 5.603 & .000 \\
\hline & DS & .162 & .067 & .171 & 2.402 & .018 \\
\hline & DMS & .281 & .080 & .283 & 3.510 & .001 \\
\hline
\end{tabular}

a. Dependent Variable: ISLP

Table nine shows how different kinds of simulation impacts student learning performance. To begin with, the B-value for the relationship between social process simulation (SPS) and student learning performance is $\mathrm{B}=.443(44.3 \%)$. This shows that an increase in the use of social process simulation in the university by one unit increases student learning performance by $44.3 \%$. The Pvalue of the association is $\mathrm{p}=.000$, which is less than .05 implying that the association or relationship is statistically significant. In this regard, hypothesis three postulating that the use of social process simulation has a positive and statistically significant impact on student learning performance is confirmed. Also, for diagnostic simulation (DS), the results are as follows: $t=$ $2.40, \mathrm{~B}, .162$, and $\mathrm{p}=.018$. This shows that there is a statistically significant association between diagnostic simulation and student learning performance since $\mathrm{p}<.05$. Similarly, as use of diagnostic simulation is increased by one unit, student learning performance is increased by $16.2 \%$. In this view, hypothesis five, the use of social process simulation has a positive and statistically significant impact on student learning performance, is confirmed. Finally, for data management simulation (DMS), $\mathrm{t}=3.51, \mathrm{~B}, .281$ and $\mathrm{p}=.001$. The $\mathrm{B}$ value indicates a positive relationship between data management simulation and student learning performance in that as DMS usage increases by one unit, student learning performance is improved by $28.1 \%$. Since $\mathrm{p}<$ .05 , it implies that the relationship is statistically significant. As such, hypothesis 6 , the use of social process simulation has a positive and statistically significant impact on student learning performance, is confirmed. 
International Journal on Integrating Technology in Education (IJITE) Vol.8, No.3, September 2019

The findings are consistent with previous research examining the impact of simulation on student and teaching outcomes. From this study, regardless of the different types of simulation approaches used in the university settings, teacher practice effectiveness, and student learning performance is positively impacted. Franklin and Lee (2014) found that simulation has positive impacts on the mastery of content which is one of the student learning performance aspects. It was recommended in the study that educators in the higher learning settings should use simulation to support student interaction and time of learning to improve their mastery of the learning content. Auman (2011) also found that in comparison with the traditional lecture method, the use of simulation-based teaching approach levels of classroom engagement among students is positively improved. In improving student engagement further, the researcher recommended further research to investigate the use of specific simulation technique and student learning outcomes. With simulation-based teaching and learning, student academic performance has been found to be greatly improved. This is because teaching and learning become enjoyable and interactive increasing motivation for learning and as such, better outcomes are obtained (Hwang \& Hahn, 2017).

The delimitations and limitations of this study lie in the methodology used in the collection and analysis of data. In general view, the study was limited to the collection of only quantitative data to accomplish its purpose of examining causal-effective associations to conclude on the impact of simulation on teaching practice effectiveness and student learning performance. In this regard, there was no in-depth understanding of how simulation can impact teaching and learning outcomes. As such, further research should combine both quantitative and qualitative methods to increase reliability of the study. This study was delimited to views of students from universities in Saudi Arabia. Further research should involve a specific department to have a full understanding of how simulation impacts teaching practice and learning of students.

\section{CONCLUSION}

From data analysis and previous literature review, this research paper has established that simulation positively impacts teaching practice effectiveness as well as student learning performance. Therefore, efforts should be focused on the development and maintenance of simulation in learning and instruction in university settings. By promoting social settings, simulation can be effective as more knowledge and information is shared. Additionally, integrating simulation in the university students' early stages in the campus will ensure they gain professional skills in different aspects of life including problem-solving, decision making and effective communication.

\section{REFERENCES}

[1] Albers, M. J. (2017). Introduction to quantitative data analysis in the behavioral and social sciences. John Wiley \& Sons.

[2] Auman, C. (2011). Using simulation games to increase student and instructor engagement. College Teaching, 59(4), 154-161.

[3] Clark, R. M., Kaw, A., \& Besterfield-Sacre, M. (2016). Comparing the effectiveness of blended, semiflipped, and flipped formats in an engineering numerical methods course. Advances in Engineering Education, 5(3), n3.

[4] Cohen, P., West, S. G., \& Aiken, L. S. (2014). Applied multiple regression/correlation analysis for the behavioral sciences. Psychology Press.

[5] Colnerud, G. (2013). The Ethical Problems of Research: An empirical study of ethics in research practice. 
International Journal on Integrating Technology in Education (IJITE) Vol.8, No.3, September 2019

[6] Dang, Y., Zhang, Y., Ravindran, S., \& Osmonbekov, T. (2016). Examining student satisfaction and gender differences in technology-supported, blended learning. Journal of Information Systems Education, 27(2), 119-130.

[7] Dolvin, S. D., \& Pyles, M. K. (2018). The impact of simulation activity on student performance. Journal of Economics and Economic Education Research, 19(3), 1-10.

[8] Franklin, A. E., \& Lee, C. S. (2014). Effectiveness of simulation for improvement in self-efficacy among novice nurses: A meta-analysis. Journal of Nursing Education, 53(11), 607-614.

[9] Grover, S., Pea, R., \& Cooper, S. (2015). Designing for deeper learning in a blended computer science course for middle school students. Computer Science Education, 25(2), 199-237.

[10] Guy, R. S., \& Lownes-Jackson, M. (2015). The use of computer simulation to compare student performance in traditional versus distance learning environments. Issues in Informing Science and Information Technology, 12, 95-109.

[11] Heale, R., \& Twycross, A. (2015). Validity and reliability in quantitative studies. Evidence-based nursing, 18(3), 66-67.

[12] Hopwood, N., Rooney, D., Boud, D., \& Kelly, M. (2016). Simulation in higher education: A sociomaterial view. Educational Philosophy and Theory, 48(2), 165-178.

[13] Hwang, J. Y., \& Hahn, K. H. (2017). A case study of 2d/3d cad virtual prototype simulation programs to enhance student performance in student-centered fashion design education. J Textile Eng Fashion Technol, 3(1), 578-584.

[14] Joshi, A., Kale, S., Chandel, S., \& Pal, D. K. (2015). Likert scale: Explored and explained. British Journal of Applied Science \& Technology, 7(4), 396.

[15] Liou, S. R., Yu, W. C., Tsai, H. M., \& Cheng, C. Y. (2015). Teaching information literacy in nursing using blended learning pedagogy. Creative Education, 6(13), 1446.

[16] López-Pérez, M. V., Pérez-López, M. C., \& Rodríguez-Ariza, L. (2011). Blended learning in higher education: Students' perceptions and their relation to outcomes. Computers \&Education, 56(3), 818826.

[17] Martini, R., Rios, J., Polatajko, H., Wolf, T., \& McEwen, S. (2015). The performance quality rating scale (PQRS): reliability, convergent validity, and internal responsiveness for two scoring systems. Disability and rehabilitation, 37(3), 231-238.

[18] McCoy, C. A. (2017). Playing Goffman's Information Game: A Classroom Activity Involving Student Interactions. Teaching Sociology, 45(3), 260-268.

[19] McGarry, D. E., Green, J. A., \& Fowler, C. (2018). Snowballing Via Facebook: A Novel Way to Recruit Millennial Nursing Student Research Participants.

[20] Miller, A. (2016). Benchmarking learner education using online business simulation. International Journal of Cyber Society and Education, 9(1), 17-34.

[21] O'Connor, C., Mortimer, D., \& Bond, S. (2011). Blended learning: Issues, benefits, and challenges. International Journal of Employment Studies, 19(2), 63.

[22] PytlikZillig, L. M., Horn, C. A., Bruning, R., Bell, S., Liu, X., Siwatu, K. O \& Carlson, D (2011). Face-to-face versus computer-mediated discussion of teaching cases: Impacts on preservice teachers' 
International Journal on Integrating Technology in Education (IJITE) Vol.8, No.3, September 2019 engagement, critical analyses, and self-efficacy. Contemporary Educational Psychology, 36(4), 302312.

[23] Rahi, S. (2017). Research design and methods: A systematic review of research paradigms, sampling issues, and instruments development. International Journal of Economics \& Management Sciences, 6(2), 1-5.

[24] Raymond, C. (2010). Do Role-Playing Simulations Generate Measurable and Meaningful Outcomes? A Simulation's Effect on Exam Scores and Teaching Evaluations. International Studies Perspectives, 11(1), 51-60.

[25] Rooney, D., Hopwood, N., Boud, D., \& Kelly, M. (2015). The role of simulation in pedagogies of higher education for the health professions: Through a practice-basedlens. Vocations and Learning, 8(3), 269-285.

[26] Taher, M., \& Khan, A. (2015). Comparison ofsimulation-based and hands-on teaching methodologies on students' learning in an engineering technology program. QScience Proceedings, 58.

[27] Vos, L. (2015). Simulation games in business and marketing education: How educators assess student learning from simulations. The International Journal of Management Education, 13(1), 57-74.

[28] Xu, Y., \& Yang, Y. (2010). Student learning in business simulation: An empirical investigation. Journal of Education for Business, 85(4), 223-228.

[29] Yamat, H. (2013). Voicing on Virtual and Face to Face Discussion. Turkish Online Journal of Educational Technology-TOJET, 12(2), 372-375.

\section{Authors}

Abdullah Alenezi, Dr. of Education, is Assistant Professor in the Educational Technology Department, Faculty of Education, Northern Borders University, Saudi Arabia. His major areas of interest and expertise are: organizational change, teaching and learning outcomes arising from uses of leading-edge technologies, implementation and management of leading-edge technologies at the local authority and individual institution levels, uses and impacts of technologies and technology-based resources in formal educational environments, distance learning and training, and technology integration in the Saudi context. 